\title{
Therapist-Driven Protocols: New Incentives for Change
}

The American Association for Respiratory Care (AARC) defines respiratory care protocols as initiation or modification of a patient care plan following a predetermined structured set of physician orders, instructions, or interventions in which the therapist is allowed to initiate, discontinue, refine, transition, or restart therapy as the patient's medical condition dictates. ${ }^{1}$

Most would agree that protocols provide a means to provide quality respiratory services; ensure that resources are consumed in only the provision of necessary care; minimize complications and cost associated with variability; bridge the relationship between physicians, nurses, and respiratory therapists; and reduce expenses for both the hospital and the patient. Evidence suggests that the quality of patient care is not diminished by the use of protocols and that cost savings can be realized by using such a strategy. ${ }^{2-4}$ Various authors have reported a decrease in the utilization of respiratory care services with protocol programs in place to defer therapy, promote the timely discontinuance of therapy, or make a transition to therapy that does not require the same labor intensity. . $^{5-7}$ Stoller et $\mathrm{al}^{8}$ demonstrated the feasibility of implementing a respiratory care consult service directed at identifying the misallocation of care in a university medical center. There is no lack of evidence regarding the benefits of the use of protocols in the delivery of respiratory care.

The protocol movement in respiratory care emerged in the early 1980s. Although the initial focus was as a mechanism to bring quality and evidence-based practice to the bedside, it became evident that substantial reductions in expense also resulted. Perhaps no one was more effective in getting the attention of the respiratory care community than Zibrak et al, ${ }^{9}$ who were among the first to report the impact of the use of the respiratory therapist as a consultant to the physician. At the beginning of their study, senior respiratory therapists advised physicians about the optimal use of various respiratory therapy services, includ-

Mr Ford has disclosed no conflicts of interest.

Correspondence: Richard M Ford RRT FAARC, Department of Pulmonary Services, University of California San Diego Health System, 200 West Arbor Drive, Mail Code 8771, San Diego, CA 92103. E-mail: rmford@ucsd.edu.

DOI: $10.4187 /$ respcare. 04123 ing their discontinuation when no longer necessary. One year after the intervention began, the authors observed that a marked reduction in all categories of respiratory therapy had occurred, but morbidity and mortality from pulmonary disorders had not increased. In the largest group studied (subjects undergoing coronary artery bypass surgery), the

\section{See the Original Study on Page 636}

charges for respiratory therapy, hospital stay, and pulmonary complications all decreased. Zibrak et $\mathrm{al}^{9}$ concluded that consistent application of prescribed guidelines for respiratory therapy results in marked decreases in its use and that such decreases can be achieved without a reduction in the quality of care. Unfortunately, consulting firms in the 1980s used Zibrak's work as evidence that reductions could easily be made in respiratory care departments without compromising care, resulting in reductions in the respiratory care workforce in departments across the country. Many consultants failed to incorporate the fact that therapists consulting with physicians drove the reductions that resulted in a decrease in the demand for services.

Efforts to find ways to reduce the cost of respiratory services were largely fueled by health-care reform. The arrangement mandated by the United States Tax Equity and Fiscal Responsibility Act of 1982 to control Medicare costs resulted in the Prospective Payment Systems. Under the new law, payment for services provided to a Medicare patient was fixed by the Centers for Medicare \& Medicaid Services, with payment based on assigned diagnosis-related groups. ${ }^{10}$ Diagnosis-related groups and other capitated payment programs shifted the focus of respiratory care departments from a revenue center to a cost center. In this environment, the profitability of hospitals was driven on the premise that less was best. The reforms of the 1980s provided the incentive for what we know today as evaluate-and-treat programs, respiratory care consult services, therapist-driven protocols, and patient-driven protocols.

Although respiratory care departments have been creative in branding the names of their programs, the profession has fallen short of using protocols as a standard of care. In 1995, the AARC published the results of a protocol-use survey that found that only $40 \%$ of hospitals were using protocols, but it was encouraging that an additional $18 \%$ were in the process of implementation. The AARC 
again formally surveyed departments in $2008^{11}$ and found: (1) $52 \%$ of hospitals had $1-5$ protocols; (2) $<8 \%$ had $>10$ protocols; (3) of those with protocols, $<50 \%$ of care was rendered using protocols; and (4) the most common protocol was for oxygen, followed by mechanical ventilation and bronchodilator therapy.

The 2008 AARC survey also indicated that medical staff support for protocols was hampered by a perceived loss of control in managing their patients. Physicians also indicated concerns that the therapist may not have the skills required to implement and refine the care plan. Finally, the perception that physicians did not have an appreciation for the clinical and economic benefits of respiratory care protocols was reported. The 2008 AARC survey concluded that: (1) medical staff are perceived as the most significant barrier to protocols, (2) most respiratory care staff do not view themselves as barriers, and (3) nearly all respiratory care staff are willing to learn additional skills to implement protocols.

In the 2014 AARC human resource surveys, ${ }^{12,13}$ therapists were asked to identify what percentage of treatments is administered by protocols. Respondents reported that $53 \%$ provide care through protocols and $21 \%$ do not use protocols, with $26 \%$ not responding. The AARC also asked the same question of managers. Managers indicated that $52 \%$ of departments provide care through protocols and $12 \%$ do not use protocols, with $36 \%$ not responding. The survey also indicated that the most common protocol was for oxygen, followed by mechanical ventilation, bronchodilator therapy, bronchial hygiene, lung hyperinflation, and disease-based protocols.

Remarkably, the incentives that drove Zibrak et al ${ }^{9}$ to pursue a method to manage the utilization of respiratory care in the 1980s still exist today. Nearly 30 years later, the vast majority of reimbursement in the acute care setting is fixed using a per patient, per day, or per stay rate. Under such systems, the use of protocols can improve the ability of hospitals to remain profitable. Despite nearly 3 decades of both fiscal and clinical incentives, the respiratory care community still has nearly as many departments that do not use protocol programs as those that do to manage the vast majority of care. The question is why. Does the failure to fully implement protocols reside in the shortcomings of leadership, staff resistance, physician resistance, lack of medical director engagement, or other system barriers?

In this issue of Respiratory CARE, Metcalf et al ${ }^{14}$ examine patterns of protocol use and features of hospitals and providers associated with respiratory care protocols. Consistent with the AARC human resource survey in 2008, they report oxygen therapy as the most used, followed by ventilator weaning and bronchial hygiene. These protocols represent a large component of services provided and thus the opportunity to make a significant impact. Providers responding to the investigators' survey indicated that the use of protocols decreases cost and improves quality of care. The authors identify that physician support is a characteristic found in centers that use protocols, as is use of high-quality information systems. The work by Metcalf et $\mathrm{al}^{14}$ falls short in providing the reader with information on why protocols fail to be widely adopted. Although further investigation may yield such detail, the respiratory care community has a new incentive to consider the use of protocols.

The Affordable Care Act (ACA) was passed by Congress and signed into law by the President on March 23, 2010, aimed at ensuring health-care quality while managing costs. The intent of the ACA was to provide new options and opportunities for affordable health-care coverage. Although the ACA retains the capitated payment models of earlier reforms, it also provides a new focus on quality. Incentives exist in which hospital payment is also dependent on several quality indicators inclusive of patient satisfaction and avoidance of readmissions. ${ }^{15}$ The Hospital Readmissions Reduction Program administers penalties for hospitals with higher than average readmission rates for a limited number of diagnosis codes, of which COPD is now included. ${ }^{16}$ If the reforms of the past 30 years have not been adequate incentive for the respiratory care community to fully adopt a protocol-driven care model, perhaps the ACA will serve as a call for action.

Although the 2014 AARC human resource survey indicated that of the $52 \%$ of care administered by protocols, $<10 \%$ was specific to COPD disease management. Protocols are now being developed around the country to ensure that best practice is applied in the transition of COPD patients from hospital to home. Findings by Werre et $\mathrm{al}^{17}$ suggest that treatment efficacy is not sacrificed when respiratory therapists direct treatment rather than physicians regardless of disease severity, and that therapist-directed protocols may have been of some benefit in reducing 30-day post-discharge readmission.

Most would agree that it simply makes no sense to invest in resources to perform a service that it not needed. Then why is it that respiratory departments throughout the country continue to provide treatment for which there may be no medical indication, no guidelines, no evidence, or no demonstrated change in outcome for a specific condition? Why is it that there is evidence for indications for noninvasive ventilation, techniques for liberation from mechanical ventilation, or how to avoid ventilator-acquired conditions and they are not incorporated into a treatment protocol or policy? Why is it that departments are shortstaffed with increasing work loads that may reduce the ability to provide quality care while at the same time using valued resources to perform unnecessary care that will make no difference to the patient outcome? I hope that after reading the article in this issue by Metcalf et al, ${ }^{14}$ 


\section{Therapist-Driven Protocols: New Incentives for Change}

readers will examine the characteristics in their own settings that serve as barriers to protocols and, in light of new reforms, will develop strategies to implement and expand respiratory care protocols.

\section{Richard M Ford RRT FAARC \\ Department of Pulmonary Services \\ University of California San Diego Health System \\ San Diego, California}

\section{REFERENCES}

1. American Association for Respiratory Care. AARC Protocol Resources. https://www.aarc.org/resources/clinical-resources/ protocols/. Accessed March 18, 2015.

2. Kester L, Stoller JK. Ordering respiratory care services for hospitalized patients: practices of overuse and underuse. Cleve Clinic J Med 1992;59(6):581-585.

3. Ford R, Phillips J, Burns D. Early results of implementing a patient driven protocol system. Respir Care 1993;38(11):1306.

4. Browning JA, Kiaser DL, Durbin CG Jr. The effect of guidelines on the appropriate use of arterial blood gas analysis in the intensive care unit. Respir Care 1989;34(3):269-276.

5. Albin RJ, Criner GJ, Thomas S, Abou-Jaoude S. Pattern of non-ICU inpatient supplemental oxygen utilization in a university hospital. Chest 1992;102(6):1672-1675.

6. Tenholder MF, Bryson MJ, Whitlock WL. A model for conversion from small volume nebulizer to metered dose inhaler aerosol therapy. Chest 1992;101(3):634-637.

7. Nielsen-Tietsort J, Poole B, Creagh CE, Repsher LE. Respiratory care protocol: an approach to in-hospital respiratory therapy. Respir Care 1981;26(5):430-436.
8. Stoller JK, Haney D, Burkhart J, Fergus L, Giles D, Hoisington E, et al. Physician-ordered respiratory care vs physician-ordered use of a respiratory therapy consult service: early experience at the Cleveland clinic foundation. Respir Care 1993;38(11):1143-1154.

9. Zibrak JD, Rossetti P, Wood E. Effect of reductions in respiratory therapy on patient outcomes. N Engl J Med 1986;315(5):292-295.

10. Buntin MB, Jain SH, Blumenthal D. Patient protection and affordable care act: laying the infrastructure for national health reform Health Affairs 2010;29(6):1214-1219.

11. American Association for Respiratory Care. Barriers to protocol implementation: survey results. A project of the AARC Protocol Implementation Committee. Irving, TX: AARC; 2008.

12. American Association for Respiratory Care. AARC Respiratory Therapist Human Resource Survey 2014. https://www.aarc.org/ resources/tools-software/aarc-respiratory-therapist-human-resourcestudy-2014/. Accessed March 18, 2015.

13. American Association for Respiratory Care. AARC Respiratory Therapist Human Resource Study 2014-Acute Care Hospital Employers. Irving, TX: AARC; 2014

14. Metcalf AY, Stoller JK, Fry TD, Habermann M. Patterns and factors associated with respiratory care protocol use. Respir Care 2015; 60(5):636-643

15. Department of Health and Human Resources Centers for Medicare \& Medicaid Services. Acute Care Hospital Inpatient Prospective Payment System Payment System Fact Sheet Series, ICN 006815, April 2013. http://www.cms.gov/Outreach-and-Education/MedicareLearning-Network-MLN/MLNProducts/downloads/ AcutePaymtSysfctsht.pdf. Accessed March 18, 2015.

16. Centers for Medicare \& Medicaid Services. Readmissions Reduction Program. http://www.cms.gov/Medicare/Medicare-Fee-for-ServicePayment/AcuteInpatientPPS/Readmissions-ReductionProgram.html. Accessed November 12, 2014.

17. Werre ND, Boucher EL, Beachey WD. Comparison of therapistdirected and physician-directed respiratory care in COPD subjects with acute pneumonia. Respir Care 2015;60(2):151-154 